\title{
Scientometrics as an Important Tool for the Growth of the Field of Learning Analytics
}

\author{
Negin Mirriahi, Dragan Gasevic, \\ Phil Long and Shane Dawson \\ Editors, Journal of Learning Analytics
}

\begin{abstract}
This article introduces the special issue from SoLAR's Learning Analytics and Knowledge conference. Learning analytics is an emerging field incorporating theory and practice from numerous disciplines to investigate how learner interactions with digital artefacts can provide actionable data to the learner herself, and educators about the learning process. As the field continues to expand there is a timely opportunity to evaluate its ongoing maturation. This evaluation could be in part informed by regular scientometric analyses from both the Journal and Conference publications. These analyses can collectively provide insight into the development of learning analytics more broadly and assist with the allocation of resources to under-represented areas for example.
\end{abstract}

KEYWORDS: Special issue, learning analytics, research, practice, Society for Learning Analytics Research, SoLAR, LAK'13

\section{EDITORIAL}

We would like to dedicate this issue to our dear colleague and friend Erik Duval from Katholieke Universiteit Leuven, Belgium. Erik has been key figure in the development of the Society for Learning Analytics Research as both executive member and prominent researcher advancing the field. At LAK'14 Indianapolis, USA, Erik informed us that he was unable to attend the conference as he had been diagnosed with non-Hodgkin lymphoma ${ }^{1}$. Despite undergoing a difficult medical treatment, Erik has maintained his unfailing level of energy, sense of humour and passion - traits which capture the hearts of those he interacts with ${ }^{2}$. Erik continues to contribute to the field of learning analytics undertaking an active role in the organization of the $2^{\text {nd }}$ Learning Analytics Summer Institute recently held at Harvard Graduate School of Education in Cambridge, MA. This issue is another endeavour which Erik has played a leading role as one of the guest editors of the special issue that was compiled based on the selected papers presented at LAK'13; the conference that Erik had organized and chaired in Leuven, Belgium. We are pleased to learn the news about the positive effects of his treatment and improvements in his health. We wish him a speedy recovery and send our collective love and support toward Leuven and his family.

\subsection{Scientometrics for the Field of Learning Analytics}

This special issue led by Ochoa, Suthers, Verbert and Duval includes an invited set of extended papers from the LAK 2013 conference held in Leuven, Belgium (Suthers, Verbert, Duval, \& Ochoa, 2013). The

\footnotetext{
${ }^{1}$ http://erikduval.wordpress.com/2014/03/31/not-so-great-news/

${ }^{2}$ http://erikduval.wordpress.com/2014/07/20/good-week/
} 
first paper, by Ochoa et al. (2014) provides a scientometric analysis of LAK2013 (Price, 1978; Van Raan, 1997), as part of their guest editorial. In so doing, the paper highlights the authorship and citation trends along with content analysis of the conference papers to illustrate the diversity of topics and research domains represented. For example, content and text analysis conducted by Ochoa et al. (2014) as part of the scientometric analysis of LAK2013 papers led to the emergence of six clusters or themes: visualizations, behaviour analysis, social learning analytics, applications, challenges, and reflections. This editorial picks up this thread to emphasise the need for continued systematic authorship, citation, and content analysis of publications to help guide and inform the development of the field of learning analytics - its research, theory, and practice.

Learning analytics research activity has rapidly progressed over the past five years. As the latest call for papers for the $5^{\text {th }}$ International conference on Learning Analytics and Knowledge (LAK'15) has been recently released ${ }^{3}$, there has been rapid growth in both conference attendance and submitted papers and workshops. From past conferences and special journals, we have seen diverse representation of academic disciplines and hence associated methodologies and practices, assumptions and theory (Dawson, Gašević, Siemens, \& Joksimovic, 2014). The commingling of various academic disciplines can provide both friction and benefits. For instance, the convergence of disciplines can result in an unanticipated paradogma or push for hegemonic status (Kirschner, 2014). This perceived concern however is outweighed by the benefits derived from interdisciplinary collaborations. The concerted effort of researchers from a broad range of disciplines, such as but not limited to computer science, education, linguistics, neuroscience, and psychology, can provide a powerful impetus for moving towards understanding complex learning processes through the amalgamation of analytical methods previously confined to particular disciplines. However, to date, the majority of published learning analytics research, whether in journals or conference proceedings has largely been conducted by nonmultidisciplinary research teams (Dawson et al., 2014). Hence, regular scientometric analysis of the state of learning analytics research can uncover whether there is a shift towards more interdisciplinary teams or if new strategies are required to facilitate greater collaboration. Further, with the progressive rise in scholarly contributions to the field, there is a need to extend conclusions drawn from various studies to practical applications to enhance learning and teaching and investigate scalability and impact of applied learning analytics.

Future publications in the Journal for Learning Analytics and the LAK conferences will continue to be fruitful resources to benchmark and evaluate the progression of this research drawing on analyses such as those presented in Ochoa et al. As the research advances we will look to integrate the associated data sets where possible as an added venue for validation and replication studies and to assist the development of the field. As an emerging analytics field we must use the tools of our trade as a means for reflection and insightful retrospection in order to advance the discipline.

\subsection{This Issue}

Many thanks for the outstanding work of Xavier Ochoa, Dan Suthers, Katrien Verbert and Erik Duval for developing this special issue. The papers selected by our guest editors for this special issue are

\footnotetext{
${ }^{3}$ http://lak15.solaresearch.org/call-for-papers
} 
representative of the various topics discussed at LAK 2013 as revealed in their scientometric analysis presented in the first paper of this issue. Continuing on from the opening paper, in the second paper, Knight, Shum, \& Littleton (2014) examine the relationships between pedagogy, assessment, and epistemology; challenging us to identify where we stand in our own learning analytic practice. In a more empirical approach, the next two papers analyze the knowledge construction process. Wise, Zhao, \& Hausknecht (2014) draw our attention to the importance of "invisible behavior" such as student message reading as well as writing of messages in online forums. Halatchliyski, Hecking, Goehnert, \& Hoppe (2014) apply main path analysis to the evolution of artifacts in a collaboratively edited Wikiversity wiki to analyze the introduction and evolution of ideas in the community. This special issue continues with two papers that focus on the evaluation of content quality. Monroy, Rangel, \& Whitaker (2014) study how learning analytics could help to assess the effectiveness and impact of digital curricula. Gunnarson and Alterman (2014), on the other hand, analyze the quality of content produced by students based on peer-promotion information. Finally, the analysis of a less digital and more hands-on type of learning is presented when Worsley and Blikstein (2014) investigate how design skills manifest themselves during the construction of physical artifacts. All these papers, diverse in topic, approaches and techniques, provide a sample of the "middle-space" that is Learning Analytics and demonstrate the growth and multifariousness of this research domain and its potential to inform learning and teaching practice.

\section{REFERENCES}

Dawson, S., Gašević, D., Siemens, G., \& Joksimovic, S. (2014). Current State and Future Trends: A Citation Network Analysis of the Learning Analytics Field. In Proceedings of the Fourth International Conference on Learning Analytics And Knowledge (pp. 231-240). New York, NY, USA: ACM. doi:10.1145/2567574.2567585

Gunnarsson, B. L., \& Alterman, R. (2014). Peer promotions as a method to identify quality content. Journal of Learning Analytics, 1(2), 126-150.

Halatchliyski, I., Hecking, T., Goehnert, T., \& Hoppe, H. U. (2014). Analyzing the Path of Ideas and Activity of Contributors in an Open Learning Community. Journal of Learning Analytics, 1(2), 72-93.

Kirschner, P. a. (2014). When a paradigm becomes a paradogma. Journal of Computer Assisted Learning, 30(4), 297-299. doi:10.1111/jcal.12074

Knight, S., Shum, S. B., \& Littleton, K. (2014). Epistemology, Assessment, Pedagogy: Where Learning Meets Analytics in the Middle Space. Journal of Learning Analytics, 1(2), 23-47.

Monroy, C., Rangel, V. S., \& Whitaker, R. (2014). A Strategy for Incorporating Learning Analytics into the Design and Evaluation of a K-12 Science Curriculum. Journal of Learning Analytics, 1(2), 94-125.

Ochoa, X., Suthers, D., Verbert, K., \& Duval, E. (2014). Analysis and reflections on the third learning analytics and knowledge conference. Journal of Learning Analytics, 1(2), 4-21.

Price, D. de S. (1978). Editorial statements. Scientometrics, 1(1), 3-8. doi:10.1007/BF02016836

Suthers, D., Verbert, K., Duval, E., \& Ochoa, X. (Eds.). (2013). Proceedings of the Third International Conference on Learning Analytics and Knowledge. New York, NY, USA: ACM.

Van Raan, A. F. (1997). Scientometrics: State-of-the-art. Scientometrics, 38(1), 205-218.

Wise, A., Zhao, Y., \& Hausknecht, S. (2014). Learning Analytics for Online Discussions: Embedded and Extracted Approaches. Journal of Learning Analytics, 1(2), 48-71. 
JOURNAL OF LEARNING ANALYTICS $\quad$ S@ 2 L AR

(2014). Scientometrics as an Important Tool for the Growth of the Field of Learning Analytics. Journal of Learning Analytics, 1(2), 1-4.

Worsley, M., \& Blikstein, P. (2014). Analyzing Engineering Design through the Lens of Computation. Journal of Learning Analytics, 1(2), 151-186. 